\title{
Macroeconomic Relationships for Russian Economic Regions
}

\author{
A.N. Bereznyatskiy ${ }^{1}$, and B.E. Brodsky ${ }^{1, *}$ \\ ${ }^{*}$ Corresponding author: bbrodsky@yandex.ru. \\ ${ }^{1}$ Central Economics and Mathematics Institute of the Russian Academy of Sciences, Moscow, Russia
}

\begin{abstract}
This paper deals with macroeconomic relationships for Russian economic regions. An economic region is the main item of the regional statistics of the Russian Federation. Nowadays there are near 90 of regions and according to classification these can be industrial, agro- or subsidized regions A study is based upon the disaggregated macromodel for the Russian economic region. Then classification of the Russian regions by types of economic activity is made. Finally, we construct macroeconomic relationships for Russian economic regions specific by their type of economic activity This paper can be considered as the first attempt to create the model of the Russian regional level.
\end{abstract}

Keywords: economy of Russia, structural modeling, disaggregated macroeconomic model, regions of Russia, applied econometric analysis.

\section{Introduction}

We can mention three main approaches to creation of applied macroeconomic models: DSGE (Dynamic Stochastic General Equilibrium modeling), VAR, and the non-equilibrium structural method (Cowles commission approach). Nowadays DSGE methods are severely criticized by modern economists [1-8].

VAR model are not often selected as methodology for creation of applied macroeconomic models. "A curse of dimensionality" is the main idea which limits the application of VAR models to the analysis of the Russian economy.

Therefore at the macro level the third approach to applied macroeconomic modeling (Cowles commission) is more often used. Below we dwell upon the basic principles of structural macroeconomic model of Russian regions.

\section{Methodology}

In the early 1990s, after the liberalization of prices and foreign trade, three macro-sectors of economic activity emerged in Russia's real production sphere. Different in terms of competition for domestic and foreign markets these sectors usually include: Export-Oriented Sector (EOS); Domestic-Oriented Sector (DOS), Natural Monopolies (NM).

So, for the proposed model the following system of assumptions is accepted: three-sector structure of the production sector; the different price's priorities in the EOS, DOS, NM; exogeneity of prices. Further, the model assumes that the products of each sector are parametricized by: $p$ - price level (base index), $Y$ - real production output, Inc aggregated income level, $D$ - total subsidies, investment into a sector.

In addition, the following symbols in the model are used: $\delta$ - the direct cost ratio, $v$ - the average nominal wage, $\omega$ - the world (export) price, $E x$, Im - real exports and imports, respectively, $\pi$ - the rate of inflation, $\beta$ - elasticity of the output with respect to the labor, $e$ - exchange rate dollar/rouble.

These variables accompanied by subscript $e, d, m$ indicating the belonging sector of EOS, DOS, NM, respectively. For example, $Y_{e}$ is a real output of EOS, $p_{d}$ the price level of DOS. Double indices are often used, for example $Y_{e m}-$ the real volume of intermediate products supplied from the EOS sector (the first index - from where?) for the NM sector (second index - where?).

Basic equations of the disaggregated 3 -sector model of the Russian economy are presented in the above papers of [9-11]. Here we point out what it means for understanding the macrodynamics of the Russian economic regions. Final equations of this model are as follows:

$$
\left(Y_{e}\right)_{t+1} \beta_{e} \alpha_{e 1}\left(1+\left(\pi_{e}\right)_{t+1}\right)=l_{e}\left(\frac{e \omega_{e}}{p_{e}} \operatorname{Ex}\left(\omega_{e}\right)+Y_{e} \alpha_{e 2}+Y_{d} \alpha_{e 3}\right)_{t}+l_{e}\left(D_{e}\right)_{t}
$$

where $\alpha_{e 1}, \alpha_{e 2}, \alpha_{e 3}$-coefficients depending on the prices ratio: $p_{d} / p_{e}, p_{m} / p_{e}$.

$$
\left(Y_{d}\right)_{t+1} \beta_{d} \alpha_{d 1}\left(1+\left(\pi_{d}\right)_{t+1}\right)=l_{e}\left(\frac{e \omega_{d}}{p_{d}} \operatorname{Ex}\left(\omega_{d}\right)+Y_{d} \alpha_{d 2}+Y_{e} \alpha_{d 3}\right)_{t}+l_{d}\left(D_{d}\right)_{t}
$$

where $\alpha_{d 1}, \alpha_{d 2}, \alpha_{d 3}$ - coefficients depending on the prices ratio: $\left(p_{e} / p_{d}\right)_{t},\left(p_{m} / p_{d}\right)_{t}$.

The resulting system of equations allows us to predict the dynamics of variables.

In particular:

any increase in the world price for crude oil and energy resources prices $\omega_{e}$ has a positive impact on the output of the EOS and DOS sectors and, as a result, on aggregate output $Y$; 
the increase in world prices for exported products of the DOS sector $\omega_{d}$ (agricultural products, weapons, high technologies) leads to an increase in the output of the DOS and EOS sectors;

the growth of the real exchange rate of the ruble $p_{d} / e$ leads to a decrease in the output of the EOS and DOS sectors;

the growth of deflated prices and tariffs for the products of the NM sector $p_{m} / p_{d}$ leads to a decrease in the output of the EOS And DOS;

the growth of the total amount of subsidies $D / p_{d}$ deflated by basic price level $p_{d}$ leads to the growth of output of truly subsidized regions;

the growth of real investment in fixed assets $I n v / p_{d}$ leads to an increase in the output of the EOS and DOS sectors. However, excessive credit resources rates $\alpha_{e}, \alpha_{d}$ will lead, on the contrary, to an increase in the number of bankruptcies of real sector enterprises and to a decrease in the output of EOS and DOS sectors.

With a small share of exports of the DOS sector output $Y_{d}$ will also be small in comparison with $Y_{e}$, and when predicting the dynamics of aggregate output, it is possible to be limited in dynamics prediction by indicator $Y_{e}$. However, when the $Y_{d}$ increases its role, the model becomes a system of two difference equations describing the dynamics of $Y_{e}$ and $Y_{e}$ indicators.

\section{Classification of the Russian regions by types of economic activity}

Classification of Russian regions by types of economic activity was done to achieve more accurate calibration of the equations of the model. A fairly simple heuristic algorithm of clustering is proposed in this report. The basic idea is: at the input of the algorithm is the GRP (gross regional product) structure vector with the normalized (by aggregate Russian values) components, the number of clusters in general is equivalent to the number of economic activity types (see [12]). We refer a region to a particular cluster by the maximum value of the ratio of the output of the corresponding type of economic activity of the region to the aggregate Russian output of the corresponding type of economic activity.

\section{Macroeconomic relationships for the Russian economic regions}

As a result, classification of the Russian regions into truly subsidized, agricultural, and industrially developed regions is proposed in the report. Then we constructed macroeconomic relationships for each type of a region. In particular, for truly subsidized regions of Russia the following relationship holds

$$
\log G R P_{t}=\alpha_{0}+\alpha_{1} \log \text { SUBSIDIES }_{t}+\varepsilon_{t}
$$

where

$G R P_{t}$ - gross regional product (deflated for base index),

SUBSIDIES $S_{t}$ - volume of subsidies to the region,

$\varepsilon_{t}$ - residuals which assumed to be stationary.

For Republic of Dagestan, from the sample 2001-2016 (yearly data) the following econometric coefficients were obtained: $\alpha_{0}=-28.075 * * *(0.931), \alpha_{1}=1.831 * * *(0.055)$ (the error level $\left.1 \%\right)$. In the above constructed system we used correction of the nominal value of SUBSIDIES for the basis price index on the consumer market of the region. After that we used the test of Dickey-Fuller ([13]), [14]) for testing stationarity (non-stationarity) of time series. This test tells us that all initial variables have the order $I(1)$. This result gives us reasons for searching cointegration relationship.

Residuals in the constructed relationship are stationary (test of Davidson-MacKinnon [15]). So, the constructed macroeconometric relationship is of true cointegration type. $R^{2}=0.98$. The analogous results were obtained for other types of regions.

\section{Conclusions}

The development of macro-model of the Russian economic region is considered in the article. The core idea (methodology and equations) of the approach is illustrated with the disaggregated macroeconomic model of Russia. The main conclusions of the analytical model are statistically tested with real data and generally confirmed at the regional level.

Classification of Russian regions by types of economic activity was done to achieve more accurate calibration of the equations of the model. It was essential to distinguish between many regions steadily (truly) subsidized, for which the influence of macro-factors could be overwhelmed by regularly received subsidies. The analysis of regions in terms of 
subsidies revealed the stability of the group of subsidized regions over time, as well as the stability of the form of the empirical curve of the distribution of regions by the index value - the ratio of accumulated subsidies of the region to the accumulated GRP.

The practical importance of the results follows from the basic idea to construct macroeconomic relationships of the Russian macroeconomic regions and to make the first attempt to create the macroeconomic model of the Russian regional level.

\section{Acknowledgements}

The authors are grateful for the support by the grant of Russian Science Foundation (project 17-18-01080).

\section{References}

1. T. Cooley, Calibrated models, Oxford Review of Economic Policy, 13(3), 55-69 (1997).

2. D.C. Colander, Testimony presented to U.S. House of Representatives Science and Technology Committee Hearing entitled "Building a Science of Economics for the Real World", Serial No. 111-106, July 20 (2010).

3. R.M. Edge, R.S. Gurkaynak, How useful are estimated DSGE model forecasts for Central Banks? Brookings Papers on Economic Activity, Economic Studies Program, the Brookings Institution, 41(2(Fall)), 209-259 (2010).

4. J. Fernandez-Villaverde, The econometrics of DSGE models, Journal of the Spanish Economic Association, 1(1), 3 49 (2010).

5. J.J. Heim, An econometric model of the US economy (Palgrave-MacMillan, London, 2017).

6. R.C. Fair, Estimating how the macroeconomy works (Cambridge Press, Harvard University, 2004).

7. N.G. Mankiw, The macroeconomist as scientist and engineer. Journal of Economic Perspectives, 20(4), 29-46 (2006).

8. R.M. Solow, Testimony presented to U.S. House of Representatives Science and Technology Committee Hearing entitled "Building a Science of Economics for the Real World", Serial No. 111-106, July 20, 2010 (2010).

9. S. Aivazian, A. Bereznyatskiy, B. Brodsky, Macroeconomic modeling of the Russian economy. Applied Econometrics, 47, 5-27 (2017). [in Rus.].

10. S. Aivazian, A. Bereznyatskiy, B. Brodsky, Modeling socio-economic dynamics of the Russian administrative branch. Bulletin of CEMI, 4 (2018). DOI: 10.33276/S0000186-7-1. [in Rus.].

11. B.E. Brodsky, S.A. Aivazian, A.N. Bereznyatskiy, Non-equilibrium structural models of the real sector of the Russian economy. Economics and Mathematical Methods, 55(2), 65-80 (2019). [in Rus.].

12. S. Aivazian, M. Afanasiev, A. Kudrov, Clustering methodology of the Russian Federation regions with account of sectoral structure of GRP. Applied Econometrics, 41, 24-46 (2016). [in Rus.].

13. D.A. Dickey, W.A. Fuller, Distributions of the estimators for the autoregressive time series with a unit root. Journal of the American Statistical Association, 74 (366), 427-431 (1979).

14.D.A. Dickey, Estimation and hypothesis testing for nonstationary time series. Retrospective Theses and Dissertations. 6267. Iowa State University (1976). URL: https://lib.dr.iastate.edu/rtd/6267. Accessed: 04.09.2019.

15. R. Davidson, J.G. MacKinnon, Estimation and inference in econometrics (Oxford University Press, New York, N.Y., 1993). 